\title{
中亚热带3种典型森林土壤碳氮含量和酶活性的 关系
}

鲍勇高颖 曾晓敏 袁 萍 司友涛 ${ }^{*}$ 陈岳民陈漟伊

福建师范大学地理科学学院, 福州 350007; 福建师范大学湿润亚热带山地生态国家重点实验室培育基地, 福州 350007

摘 要 森林类型更替是影响生态系统有机质循环的重要因素, 它对森林生态系统的生产力、碳吸存和养分保持功能有影 响。然而关于中亚热带不同森林类型对土壤碳氮含量和酶活性的影响及土壤碳氮含量和酶活性之间的关系鲜有报道。该文研 究了福建省三明市3种典型亚热带森林——米槠(Castanopsis carlesii)天然次生林(SF)、米槠人工促进天然更新林(AR)、马尾 松(Pinus massoniana)人工林(PM)的淋溶层(A层)土壤碳氮含量和土壤微生物酶活性的关系。结果表明: 在3种森林类型表层土 壤中, 可溶性有机质中可溶性有机碳、可溶性有机氮(DON)、苂光发射光谱腐殖化指数的趋势均为 $\mathrm{SF}>\mathrm{AR}>\mathrm{PM}$, 芳香化指 数大小为 $\mathrm{PM}>\mathrm{AR}>\mathrm{SF} ; \mathrm{SF}$ 和 $\mathrm{AR}$ 的 $\mathrm{NH}_{4}^{+}-\mathrm{N}$ 显著高于 $\mathrm{PM}, \mathrm{NO}_{3}^{-}-\mathrm{N}$ 在3种林分中的含量低且差异不明显, 造成这种差异的原因是 树种差异和人为干扰程度不同。 $\mathrm{PM}$ 的 $\beta$-葡萄糖苷酶活性显著低于 $\mathrm{SF}$ 和 $\mathrm{AR}$; 纤维素水解酶活性大小为 $\mathrm{AR}>\mathrm{SF}>\mathrm{PM}$; PM多酚 氧化酶显著高于SF和AR, 3 种林分过氧化物酶无显著差异。AR的 $\beta-N$-乙酰氨基葡萄糖苷酶(NAG)显著高于其他两种林分。圥 余分析显示土壤总氮和DON是驱动淋溶层土壤酶活性的主要环境因子。总之, 土壤总氮含量与NAG活性呈正相关关系, 并且 可溶性有机氮可能是氮循环中的重要一环; 土壤微生物优先利用易分解碳; 且碳氮养分循环之间存在一定的耦合关系。氮提 高了与土壤碳相关的水解酶活性, 从而可促进碳周转。

关键词＼cjkstart森林类型; 可溶性有机质; 碳氮养分; 酶活性; 土壤碳氮循环

鲍勇, 高颖, 曾晓敏, 袁萍, 司友涛, 陈岳民, 陈港伊 (2018). 中亚热带3种典型森林土壤碳氮含量和酶活性的关系. 植物生态学报, 42, 508-516. DOI: 10.17521 /cjpe.2017.0311

\section{Relationships between carbon and nitrogen contents and enzyme activities in soil of three typical subtropical forests in China}

BAO Yong, GAO Ying, ZENG Xiao-Min, YUAN Ping, SI You-Tao*, CHEN Yue-Min, and CHEN Ying-Yi

School of Geography Sciences, Fujian Normal University, Fuzhou 350007, China; and State Key Laboratory of Sub-tropical Mountain Ecology (Founded by Ministry of Science and Technology and Fujian Province), Fujian Normal University, Fuzhou 350007, China

\section{Abstract}

Aims Forest conversion is an important factor affecting the ecosystem organic matter cycle, and has an impact on the productivity of forest ecosystems, carbon sequestration and nutrient conservation. This study aims to provide more scientific evidence for better understanding the mechanism of different forest types regulating forest soil carbon and nitrogen cycling in the context of forest conversion.

Methods The study site is located in Sanming City, Fujian Province, in subtropical China. Soil samples in the A horizon from an artificial-assisted natural regeneration forest of Castanopsis carlesii (AR), a natural secondary forest of C. carlesii (SF) and a plantation of Pinus massoniana (PM) sites were collected in November, 2016. We investigated the contents of soil organic carbon, soil organic nitrogen, soil dissolved organic matter (DOM), $\mathrm{NH}_{4}^{+}-\mathrm{N}$ and $\mathrm{NO}_{3}^{-}-\mathrm{N}$. The spectroscopic characteristics of soil DOM were also measured by means of ultraviolet absorbance and fluorescence emission spectroscopic techniques. The activity of five kinds of enzymes related to carbon and nitrogen cycle were determined to decipher their relationships with soil properties.

Important findings The results showed that, due to different tree species and man-made disturbance, the contents of dissolved organic carbon (DOC), DON, humification index of fluorescence emission spectrum were all in the order $\mathrm{SF}>\mathrm{AR}>\mathrm{PM}$, whereas the aromatization index was in the order $\mathrm{PM}>\mathrm{AR}>\mathrm{SF}$. $\mathrm{NH}_{4}^{+}-\mathrm{N}$ were

收稿日期Received: 2017-11-29 接受日期Accepted: 2018-03-15

基金项目：国家自然科学基金(31570606)和福建省自然科学基金(2015J01120)。Supported by the National Natural Science Foundation of China (31570606), and the Natural Science Foundation of Fujian Province (2015J01120).

* 通信作者Corresponding author (yt.si@fjnu.edu.cn) 
significantly richer for $\mathrm{SF}$ and $\mathrm{AR}$ than for $\mathrm{PM}$, while $\mathrm{NO}_{3}^{-}-\mathrm{N}$ content was low and similar across the three stands. The $\beta$-glucosidase activity of PM was significantly lower than that of SF and AR. The activities of cellulolytic enzyme were in sequence of AR $>$ SF $>$ PM. The activities of polyphenol oxidase enzyme in PM was significantly higher than in SF and AR. There was no significant difference in the type of forest peroxidase. The activity of $\beta$-N-acetylglucosaminidase of AR was significantly higher than those of the other two kinds of stands. The redundancy analysis indicates that total nitrogen $(\mathrm{TN})$ and DON are the major environmental factors driving soil enzyme activity. Soil total nitrogen content and NAG activity were positively correlated, and DON may be an important component of the $\mathrm{N}$ cycle. Soil microorganisms prefer to use readily decomposable carbon; and there is a certain coupling relationship between carbon and nitrogen cycles. Higher soil $\mathrm{N}$ contents would increase the C-related hydrolytic enzyme activity, thereby promoting carbon turnover.

Key words forest type; dissolved organic matter; carbon and nitrogen nutrients; enzyme activity; soil carbon and nitrogen cycle

Bao Y, Gao Y, Zeng XM, Yuan P, Si YT, Chen YM, Chen YY (2018). Relationships between carbon and nitrogen contents and enzyme activities in soil of three typical subtropical forests in China. Chinese Journal of Plant Ecology, 42, 508-516. DOI: $10.17521 /$ cjpe. 2017.0311

森林生态系统是陆地生态系统最主要的碳库 (Houghton, 2007), 作为全球碳循环的重要组成部分, 在全球碳循环中扮演着重要角色 (Sedjo, 1992; Jobbágy \& Jackson, 2000)。森林类型更替会改变地 上植被群落组成, 以及细根和调落物向土壤的有机 质输入, 使输入土壤的可溶性有机质(DOM)数量和 质量发生变化。土壤DOM作为土壤养分中十分活跃 的组分, 虽只占土壤养分库的一小部分, 却极容易 被微生物利用, 影响微生物的生长代谢(Zhao et al., 2003), 从而改变土壤的养分环境。土壤微生物需要 从土壤中获取能量和养分来满足自身的生长代谢, 从而参与到土壤碳氮的生物化学循环过程中。土壤 环境一旦改变, 微生物活性也会随之改变, 其活性 主要体现在胞外酶上, 它对土壤有机质进行矿化分 解被认为是养分循环的关键环节。酶是有机质分解、 周转和矿化的主要生物催化剂(Burns, 1982; Frankenberger \& Dick, 1983)。研究发现随着土壤有机质 的积累, 生态系统的生产力越来越依赖于胞外酶的 矿化分解作用(Waldrop \& Firestone, 2004; Condron et al., 2005; Parfitt et al., 2005)。

酶活性的大小可以指示微生物养分需求和土壤 养分供给之间的关系。大多数研究表明, 土壤养分 含量和酶活性之间呈负相关关系, 即随着无机或有 机形式的营养物质的增加, 微生物获取该营养物质 的难度降低, 所需的相关催化酶的活性也相应降低 (Allison \& Vitousek, 2005; Burns et al., 2013)。然而, Debosz等(1999)的研究表明输入有机物使纤维素酶 活性增强; Taylor等(2002)的研究结果也显示, 酶活 性与土壤有机质之间存在显著的正相关关系。因此
生态系统养分含量与酶活性之间的明确关系目前还 没有定论。同时，由于土壤中各元素之间存在耦合 关系, 养分有效性和酶活性之间还依赖于其他元素 含量的高低, 含量相对高的元素可能会促进胞外酶 对另一种元素的分解利用, 例如氮的有效性将会影 响碳分解酶的活性, 进而改变调落物及土壤有机质 的分解速率(Sinsabaugh, 2010)。

目前, 关于森林土壤酶的研究主要集中在欧洲 和北美洲的北方森林或温带森林，以外源养分添加 对酶的影响居多, 对亚热带不同森林类型中内源养 分与酶的关系研究较少(莫江明等, 2004)。我国中亚 热带地区, 由于雨水充沛, 森林群落种类丰富, 土 壤可溶性养分多, 森林在生态过程中的作用比温带 更大，是全球同纬度地带上的“绿洲”，有着旺盛的 能量转化和物质循环的能力, 以及极强的生物生产 力与生态效应, 是全球碳氮循环的重要组成部分 (吴波波等, 2014)。在过去几十年中, 我国中亚热带 地区发生着剧烈的森林类型更替, 大面积的天然常 绿阔叶林经过强烈人为干扰后, 转变为次生林和人 工林, 但这种人为干扰对森林生态系统的生产力、 碳吸存和养分保持功能所产生的影响至今并不清楚, 森林类型更替后各林分类型中土壤碳氮养分和酶活 性之间有何关系和变化也不清楚。本文选取典型的 米槠(Castanopsis carlesii)天然次生林、米槠人工促 进天然更新林、马尾松(Pinus massoniana)人工林为 研究对象, 探索不同森林类型土壤碳氮含量和土壤 酶活性之间的关系, 为中亚热带陆地土壤碳、氮等 物质循环提供科学依据, 为森林经营方式的合理调 整及未来森林更新方式的选择提供科学参考。 


\section{1 材料和方法}

\section{1 研究样地概况}

研究地区位于福建三明森林生态系统与全球变 化野外观测研究站陈大观测点 $\left(26.32^{\circ} \mathrm{N}, 117.60^{\circ} \mathrm{E}\right)$, 地处武夷山东南, 戴云山脉西北。地貌以低山丘陵 为主, 山地平均坡度 $25^{\circ}-35^{\circ}$, 属中亚热带海洋季风 气候, 年平均气温 $19.1{ }^{\circ} \mathrm{C}$, 年降水量 $1749 \mathrm{~mm}$, 年 蒸发量 $1585 \mathrm{~mm}$, 相对湿度 $81 \%$, 全年无霜期达 300 天。区域内地带性植被为常绿阔叶林, 亦分布有一 定面积的针阔混交林和针叶林(胥超等, 2017)。

该试验样地主要包括3种典型的亚热带森林类 型——米槠天然次生林 $(\mathrm{SF})$ 、米槠人工促进天然更 新林( $\mathrm{AR}$ )和马尾松人工林(PM), 即为试验的 3 个处 理, 每个处理设 3 个重复。3 种森林类型的林龄相近, 且具有相同的立地条件, 在转换之前均为米槠天然 林(200年左右未受干扰)。其中, SF由米槠天然林经 过择伐后封山育林再经过自然次生演替形成, 海拔 $330 \mathrm{~m}$ ，坡度 $40^{\circ}$, 形成时间 40 年，林分密度为 3788 株. $\mathrm{hm}^{-2}$, 平均树高 $10.8 \mathrm{~m}$, 平均胸径 $12.2 \mathrm{~cm}$, 土壤 容重 $1.16 \mathrm{~g} \cdot \mathrm{cm}^{-3}$ 。主要树种有米槠、闽粤栲 (Castanopsis fissa)等。AR为采伐时保留林下幼树, 采伐后保留剩余物, 并沿水平带平铺堆积残留的枝 桠、树梢等以促其腐烂形成的人工促进更新林, 海 拔 $335 \mathrm{~m}$, 坡度 $38^{\circ}$, 形成时间 40 年, 林分密度为 2158 株 $\cdot \mathrm{hm}^{-2}$, 平均树高 $13.7 \mathrm{~m}$, 平均胸径 $16.8 \mathrm{~cm}$, 土壤容重 $1.21 \mathrm{~g} \cdot \mathrm{cm}^{-3}$ 。其主要树种有米槠、东南野 桐(Malloyus lianus)等。PM为皆伐后, 经火烧、挖穴 造林和幼林抚育营造的人工纯林, 林冠单层, 海拔 $313 \mathrm{~m}$, 坡度 $38^{\circ}$, 形成时间 41 年, 林分密度为 1500 株. $\mathrm{hm}^{-2}$, 平均树高 $18.3 \mathrm{~m}$, 平均胸径 $18.3 \mathrm{~cm}$, 土壤 容重 $1.33 \mathrm{~g} \cdot \mathrm{cm}^{-3}$ 。林下植被覆盖度约为 $90 \%$, 灌木较 少, 以芒萁(Dicranopteris pedata)、芒(Miscanthus sinensis)和硕(Pteridium aquilinum)等草本植物为主。

\section{2 土壤样品采集和处理}

2016年11月进行采样。每块样地按照“S”形随机 设定 5 个取样点, 去除表面调落物后采集淋溶层(A 层), 将土样混合均匀。土样低温保鲜运回实验室进行 分析, 一部分去除石砾、植物根系过 $2 \mathrm{~mm}$ 篮后 $4{ }^{\circ} \mathrm{C}$ 储存, 用于土壤养分 $(\mathrm{DOM}) 、$ 铵态氮 $\left(\mathrm{NH}_{4}^{+}-\mathrm{N}\right)$ 和硝态 氮 $\left(\mathrm{NO}_{3}^{-}-\mathrm{N}\right)$ 和土壤理化性质 $(\mathrm{pH}$ 值、含水率、土壤总 有机碳 (SOC) 和土壤总氮 $(\mathrm{TN})$ ) 的测定; 另一部分保 存在 $-20{ }^{\circ} \mathrm{C}$ 冷藏, 用于后续的微生物酶活性试验。

\section{3 土壤基本理化性质的测定}

土壤有机碳及全氮用碳氮元素分析仪 (Elementar Vario EL III, Elementar, German)测定, $\mathrm{pH}$ 值用 CHN868 型 $\mathrm{pH}$ 计测定, 水土体积质量比为 2.5:1。采用烘干法测定质量含水率。

\section{4 土壤铵态氮和硝态氮浓度测定}

采用 $\mathrm{KCl}$ 溶液浸提法(苏涛等, 2005), 取 $5 \mathrm{~g}$ 过 $2 \mathrm{~mm}$ 篮的鲜土于离心管中, 加入 $20 \mathrm{~mL} 2.0 \mathrm{~mol} \cdot \mathrm{L}^{-1}$ $\mathrm{KCl}$ 溶液, 振荡 $30 \mathrm{~min}$ 后离心 $30 \mathrm{~min}\left(4000 \mathrm{r} \cdot \mathrm{min}^{-1}\right)$, 用 $0.45 \mu \mathrm{m}$ 滤膜过滤, 使用连续流动分析仪(San++, Skalar, Breda, the Netherlands)测定滤液中的土壤 $\mathrm{NH}_{4}^{+}-\mathrm{N}$ 和 $\mathrm{NO}_{3}^{-}-\mathrm{N}$ 浓度。

\section{$1.5 \mathrm{DOM}$ 提取与可溶性有机碳(DOC)、可溶性有 机氮(DON)浓度测定}

样品DOM采用水浸提法(Wu et al., 2010), 取 $15 \mathrm{~g}$ 过 $2 \mathrm{~mm}$ 篎的鲜土于离心管中, 加入去离子水 (水土体积质量比 $2: 1$ ), 振荡 $30 \mathrm{~min}$ 后离心 $10 \mathrm{~min}$ (4 $000 \mathrm{r} \cdot \mathrm{min}^{-1}$ ), 用 $0.45 \mu \mathrm{m}$ 滤膜过滤, 滤液中的有机 物即为 DOM。采用有机碳分析仪 (TOC-VCPH, Shimadzu, Kyoto, Japan)测定样品DOC浓度, 使用连 续流动分析仪测定DON浓度。

\section{6 光谱分析测定}

用紫外-可见光分光度计(UV-2450, Shimadzu, Kyoto, Japan)测定 $254 \mathrm{~nm}$ 的吸光度值。利用待测液 $254 \mathrm{~nm}$ 处吸收值(SUVA)分析其芳香化程度和疏水 特性(Akagi et al., 2007), 计算芳香化指数(AI)(Saadi et al., 2006): $A I=\left(\mathrm{UV}_{254} / C\right) \times 100$

式中: $\mathrm{UV}_{254}$ 为 $254 \mathrm{~nm}$ 的吸光度值 $\left(\mathrm{cm}^{-1}\right)$; $C$ 为DOC浓 度 $\left(\mathrm{mg} \cdot \mathrm{L}^{-1}\right)$ 。

用F-7000荧光分光光度计(Hitachi, Tokyo, Japan) 测定样品的苂光发射光谱, 测定方法及参数设定参 照文献(刘翥等, 2014)。荧光发射光谱腐殖化指数 $\left(H I X_{\mathrm{em}}\right)$ 为荧光发射光谱中波长 435-480 $\mathrm{nm}$ 与波长 300-345 nm的面积比(Kalbitz et al., 1999; Zsolnay et al., 1999)。为提高灵敏度, 荧光光谱测定前使用 2 $\mathrm{mol} \cdot \mathrm{L}^{-1} \mathrm{HCl}$ 将所有待测液的 $\mathrm{pH}$ 值调成2 (Akagi et al., 2007)。HIX $X_{\mathrm{em}}$ 可用来表征DOM的腐殖化程度, $H I X_{\mathrm{em}}$ 越大，说明DOM中分子构成越复杂， $\pi-\pi$ 共轭 体系越大，腐殖类物质如缩合芳环和大分子化合物 的含量越高(Bu et al., 2010)。

\section{7 酶活性的测定}

参照Saiya-Cork (2002)的方法, 提取和培养土 
壤中 5 种与碳、氮循环相关的水解酶和氧化酶。方法 如下: 取 $1 \mathrm{~g}$ 新鲜土壤, 用 $125 \mathrm{~mL} 50 \mathrm{mmol} \cdot \mathrm{L}^{-1}$ 的醋 酸盐缓冲液 $(\mathrm{pH}=5)$ 提取, 用磁力搅拌器搅拌 $5 \mathrm{~min}$ 使其均质化, 用移液器取 $200 \mu \mathrm{L}$ 移于 96 孔微孔板。 用伞形酩(MUB)作为底物标示水解酶活性, 用 L-二 羟苯丙氨酸(DOPA)为底物标示氧化酶活性。微平板 置于暗环境下经过 $20{ }^{\circ} \mathrm{C}$ 恒温培养后, 用多功能酶标 仪(SpectraMax M5, Molecular Devices, Sunnyvale, USA)测定其苂光度(水解酶)或吸光度(氧化酶)。底 物以碳为主的多糖(纤维素)、芳香族化合物(木质素) 和脂肪族化合物, 其分解酶主要为纤维素水解酶类 $(\beta$-葡萄糖苷酶 $(\beta \mathrm{G})$ 和纤维素水解酶 $(\mathrm{CBH})$ 和木质素 分解酶类多酚氧化酶( $\mathrm{PHO}$ )和过氧化物酶(PEO))。底 物为以氮为主的氨基化合物、缩氨酸和非缩氨基化 合物，其分解酶为 $\beta-\mathrm{N}$-乙酰氨基葡萄糖苷酶 $(\mathrm{NAG})$ (Knicker et al., 1981)。5种土壤酶的名称、缩写、功 能及所用标定底物见表 1 。各种酶都通过预实验确定 获得最大酶活性所需要的底物浓度和培养时间。

\section{8 数据分析}

用Excel 2013和SPSS 21.0软件对数据进行处 理。采用单因素方差分析和最小显著差异法 $(L S D)$ 检验不同林型土壤理化性质、碳氮养分含量和酶活 性的差异显著性, 显著性水平设定为 $p=0.05$; 采用 Canoco Software 5.0软件, 以土壤酶活性为响应变 量, 同时以土壤养分以及土壤基本理化性质为解释 变量做圥余分析(RDA)。用Origin 9.0软件绘图。

\section{2 结果}

\section{1 各林分类型土壤基本理化性质和有效养分}

由表2可知，土壤 $\mathrm{pH}$ 值在4.55-4.79之间，不同 林分类型间差异均不显著。AR含水率显著高于其他 两种林分。PM土壤有机碳含量显著低于其他两种林
分类型。3种林分类型全氮含量差异显著, 表现为 $\mathrm{AR}>\mathrm{SF}>\mathrm{PM}$; $\mathrm{SF}$ 和 $\mathrm{AR}$ 的土壤 $\mathrm{C} / \mathrm{N}$ 显著高于 $\mathrm{PM}$ $(p<0.05)$ 。

$\mathrm{SF}$ 和 $\mathrm{AR}$ 的 $\mathrm{NH}_{4}^{+}-\mathrm{N}$ 含量显著高于 $\mathrm{PM}$, 且 $\mathrm{AR}$ 最高; 3 种林分中 $\mathrm{NO}_{3}^{-}-\mathrm{N}$ 无显著差异。 $\mathrm{SF}$ 和 $\mathrm{AR}$ 土壤 $\mathrm{DOC}$ 浓 度分别是 $\mathrm{PM}$ 的 3.3 和 2.9 倍, 差异达到显著水平 $(p<$ $0.05)$; $\mathrm{SF}$ 土壤DON浓度最高, 为 $8.80 \mathrm{mg} \cdot \mathrm{kg}^{-1}$, 但与 其他两种林分差异不显著。

\section{2 各林分土壤DOM芳香化和腐殖化指标}

如图1所示, SF 的 $A I$ 显著低于 $\mathrm{AR}$ 和 $\mathrm{PM}(p<$ $0.05)$ 。 $A R$ 和 $P M$ 分别是 $S F$ 的 1.87 和 2.19 倍。 $\mathrm{SF}$ 的 $H I X_{\mathrm{em}}$ 显著高于 $\mathrm{AR}$ 和 $\mathrm{PM}(p<0.05)$, 分别是 $\mathrm{AR}$ 和 $\mathrm{PM}$ 的1.30和1.49倍。 $\mathrm{AR}$ 与 $\mathrm{PM}$ 的 $H I X_{\mathrm{em}}$ 无显著差异。

\section{3 不同林分的土壤酶活性}

$\mathrm{PM}$ 的 $\beta \mathrm{G}$ 活性显著低于 $\mathrm{SF}$ 和AR $(p<0.05) ; 3$ 种 林分 $\mathrm{CBH}$ 活性差异显著, 表现为 $\mathrm{AR}>\mathrm{SF}>\mathrm{PM}$; $\mathrm{PM}$ 的PHO活性显著高于 $\mathrm{SF}$ 和AR $(p<0.05), 3$ 种林分 PEO活性无显著差异(表3)。AR的NAG活性显著高 于其他两种林分 $(p<0.05)$ 。

\section{4 土壤酶活性变化的RDA分析}

以 5 种土壤酶活性为响应变量, 以土壤理化性 质和有效养分为解释变量, 对 3 种森林类型 $\mathrm{A}$ 层土壤 酶活性进行午余分析, 从而探究土壤理化性质、有 效养分和微生物胞外酶活性之间的相关关系。我们 只选择了贡献率达到显著水平的两个解释变量。如 图2所示, 3种林分土壤酶活性在第一轴上可以较明 显地区分开来, 第一轴主要由 $\beta \mathrm{G} 、 \mathrm{CBH}$ 和PHO 3 种 酶控制，第一轴可以解释酶活性总变异的 $74.63 \%$, 影响这3种酶的主要因素是 $\mathrm{TN}$ 。第二轴主要由NAG 酶控制, 解释了其酶活性总变异的 $9.74 \%$ 。 $\mathrm{TN}$ 和 $\mathrm{DON}$ 分别解释了土壤酶活性变化的 $71.2 \%(p=$ $0.002)$ 和 $13.2 \%(p=0.012)$ 。 $\mathrm{TN}$ 与 $\beta \mathrm{G} 、 \mathrm{CBH} 、 \mathrm{NAG}$

表1 土壤酶的名称、缩写、功能及底物

Table 1 The abbreviations, function and substrates of soil enzyme

\begin{tabular}{|c|c|c|c|}
\hline $\begin{array}{l}\text { 酶 } \\
\text { Enzyme }\end{array}$ & $\begin{array}{l}\text { 缩写 } \\
\text { Abbreviation }\end{array}$ & $\begin{array}{l}\text { 功能 } \\
\text { Function }\end{array}$ & $\begin{array}{l}\text { 底物 } \\
\text { Substrate }\end{array}$ \\
\hline $\begin{array}{l}\beta \text {-葡萄糖苷酶 } \\
\beta \text {-glucosidase }\end{array}$ & $\beta G$ & 分解易降解碳 Decomposition of labile carbon & $\begin{array}{l}\text { 4-甲基伞形酮- } \beta \text {-D-葡萄糖苷 } \\
\text { 4-methylumbelliferyl- } \beta \text {-D-glucoside }\end{array}$ \\
\hline $\begin{array}{l}\text { 纤维素水解酶 } \\
\text { Cellulose hydrolysis }\end{array}$ & $\mathrm{CBH}$ & 分解易降解碳 Decomposition of labile carbon & $\begin{array}{l}\text { 4-甲基伞形酮- } \beta \text {-D-纤维素二糖苷 } \\
\text { 4-methylumbelliferyl- } \beta \text {-D-cellobioside }\end{array}$ \\
\hline $\begin{array}{l}\beta-\mathrm{N} \text {-乙酰氨基葡萄糖苷酶 } \\
\beta-\mathrm{N} \text {-acetylglucosaminidase }\end{array}$ & NAG & 分解氮 Hydrolyze nitrogen & $\begin{array}{l}\text { 4-甲基伞形酮-2-乙酰氨基-2-脱氧- } \beta \text {-D-吡喃葡萄糖苷 } \\
\text { 4-methylumbelliferyl-N-acetyl- } \beta \text {-D-glucosaminide }\end{array}$ \\
\hline 多酚氧化酶 Phenol oxidase & PHO & 分解难降解碳 Decomposition of recalcitrant carbon & 二羟基苯 L-dihydroxyphenylalanine \\
\hline 过氧化物酶 Peroxidase & PEO & 分解难降解碳 Decomposition of recalcitrant carbon & 二羟基苯 L-dihydroxyphenylalanine \\
\hline
\end{tabular}


表2 不同林分类型的主要土壤理化性质和有效养分(平均值土标准偏差, $n=3$ )

Table 2 Main soil physical and chemical properties and soil available nutrients in different forest types $(\operatorname{mean} \pm S D, n=3)$

\begin{tabular}{|c|c|c|c|c|c|c|c|c|c|}
\hline $\begin{array}{l}\text { 林分类型 } \\
\text { Forest type }\end{array}$ & $\mathrm{pH}$ & $\begin{array}{c}\text { 含水率 } \\
\text { Moisture } \\
(\%)\end{array}$ & $\begin{array}{c}\text { 土壤总有机碳 } \\
\text { Total soil } \\
\text { organic carbon } \\
\left(\mathrm{g} \cdot \mathrm{kg}^{-1}\right)\end{array}$ & $\begin{array}{c}\text { 全氮 } \\
\text { Total } \\
\text { nitrogen } \\
\left(\mathrm{g} \cdot \mathrm{kg}^{-1}\right)\end{array}$ & $\mathrm{C}: \mathrm{N}$ & $\begin{array}{c}\mathrm{NH}_{4}^{+}-\mathrm{N} \\
\left(\mathrm{mg} \cdot \mathrm{kg}^{-1}\right)\end{array}$ & $\begin{array}{c}\mathrm{NO}_{3}^{-}-\mathrm{N} \\
\left(\mathrm{mg} \cdot \mathrm{kg}^{-1}\right)\end{array}$ & $\begin{array}{c}\text { 可溶性有机碳 } \\
\text { Dissolved } \\
\text { organic carbon } \\
\left(\mathrm{mg} \cdot \mathrm{kg}^{-1}\right)\end{array}$ & $\begin{array}{c}\text { 可溶性有机氮 } \\
\text { Dissolved } \\
\text { organic nitrogen } \\
\left(\mathrm{mg} \cdot \mathrm{kg}^{-1}\right)\end{array}$ \\
\hline SF & $4.72 \pm 0.18^{\mathrm{a}}$ & $27.24 \pm 1.42^{\mathrm{b}}$ & $41.69 \pm 1.46^{\mathrm{a}}$ & $2.43 \pm 0.11^{\mathrm{b}}$ & $17.20 \pm 0.50^{\mathrm{a}}$ & $80.17 \pm 5.10^{\mathrm{a}}$ & $7.67 \pm 1.93^{\mathrm{a}}$ & $87.47 \pm 29.59^{\mathrm{a}}$ & $8.80 \pm 2.28^{\mathrm{a}}$ \\
\hline $\mathrm{AR}$ & $4.79 \pm 0.10^{\mathrm{a}}$ & $35.02 \pm 0.56^{\mathrm{a}}$ & $45.82 \pm 5.64^{\mathrm{a}}$ & $2.89 \pm 0.16^{\mathrm{a}}$ & $15.80 \pm 1.03^{\mathrm{a}}$ & $92.40 \pm 3.76^{\mathrm{a}}$ & $4.83 \pm 2.80^{\mathrm{a}}$ & $76.98 \pm 12.55^{\mathrm{a}}$ & $6.68 \pm 2.28^{\mathrm{a}}$ \\
\hline PM & $4.63 \pm 0.06^{\mathrm{a}}$ & $28.79 \pm 2.49^{b}$ & $25.16 \pm 0.52^{b}$ & $1.83 \pm 0.04^{\mathrm{c}}$ & $13.73 \pm 0.59^{b}$ & $54.47 \pm 11.28^{\mathrm{b}}$ & $6.50 \pm 0.24^{\mathrm{a}}$ & $26.55 \pm 6.44^{b}$ & $5.84 \pm 1.46^{\mathrm{a}}$ \\
\hline
\end{tabular}

$\mathrm{SF}$, 米槠天然次生林; $\mathrm{AR}$, 米槠人工促进天然更新林; PM，马尾松人工林。不同小写字母表示不同林分间差异显著 $(p<0.05)$ 。

SF, natural secondary forest of Castanopsis carlesii; AR, artificial-assisted natural regeneration forest of Castanopsis carlesii; PM, plantation of Pinus massoniana. Different lowercase letters indicate significant difference among different stands $(p<0.05)$.
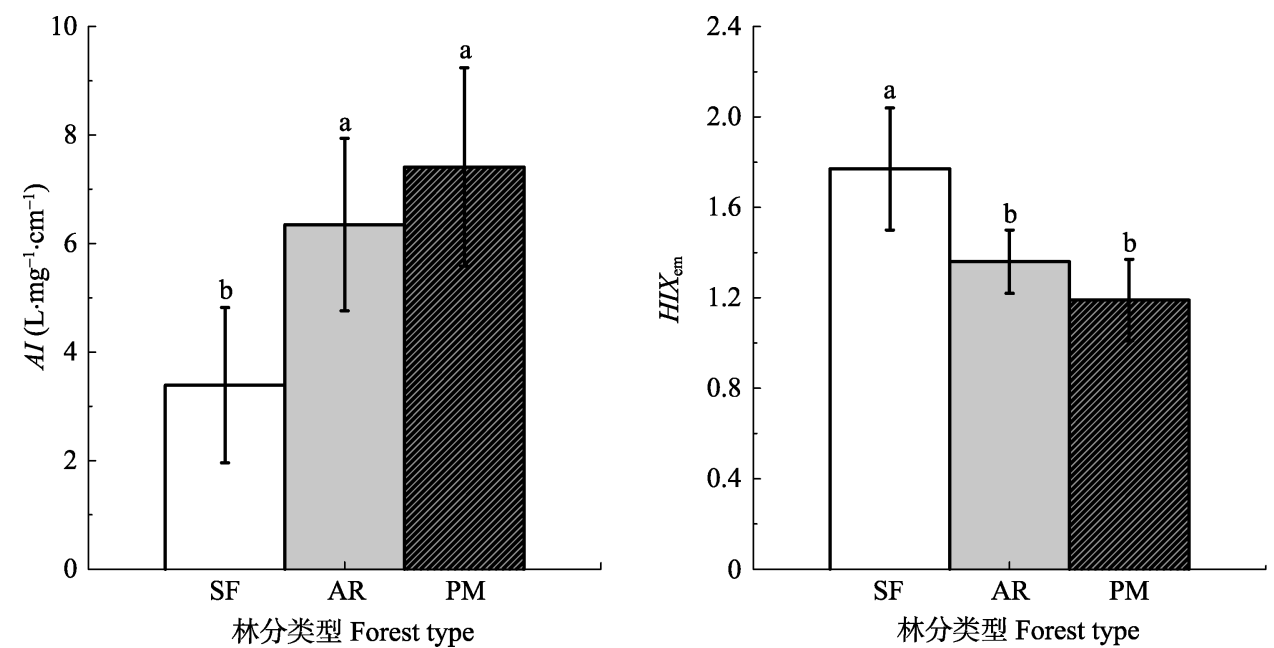

图1 不同林分土壤的芳香化指数 $(A I)$ 和荧光发射光谱腐殖化指数 $\left(H I X_{\mathrm{em}}\right)$ (平均值土标准偏差, $\left.n=3\right)$ 。 $\mathrm{SF}$, 米槠天然次生林; $\mathrm{AR}$, 米槠人工促进天然更新林; PM，马尾松人工林。不同小写字母表示不同林分间差异显著 $(p<0.05)$ 。

Fig. 1 Aromatic index $(A I)$ and humification index emission mode $\left(H I X_{\text {em }}\right)$ in different forests (mean $\left.\pm S D, n=3\right)$. SF, natural secondary forest of Castanopsis carlesii; AR, artificial-assisted natural regeneration forest of Castanopsis carlesii; PM, plantation of Pinus massoniana. Different lowercase letters indicate significant difference among different stands $(p<0.05)$.

表3 不同林分类型的土壤酶活性(平均值土标准偏差, $n=3$ )

Table 3 Soil enzyme activities in different forest types (mean $\pm S D, n=3)$

\begin{tabular}{|c|c|c|c|c|c|}
\hline 林分类型 Forest type & $\beta \mathrm{G}\left(\mathrm{nmol} \cdot \mathrm{g}^{-1} \cdot \mathrm{h}^{-1}\right)$ & $\mathrm{CBH}\left(\mathrm{nmol} \cdot \mathrm{g}^{-1} \cdot \mathrm{h}^{-1}\right)$ & $\mathrm{NAG}\left(\mathrm{nmol} \cdot \mathrm{g}^{-1} \cdot \mathrm{h}^{-1}\right)$ & PHO $\left(\mu \mathrm{mol} \cdot \mathrm{g}^{-1} \cdot \mathrm{h}^{-1}\right)$ & $\operatorname{PEO}\left(\mu \mathrm{mol} \cdot \mathrm{g}^{-1} \cdot \mathrm{h}^{-1}\right)$ \\
\hline $\mathrm{SF}$ & $38.93 \pm 7.44^{\mathrm{a}}$ & $1.41 \pm 0.29^{b}$ & $36.42 \pm 7.68^{b}$ & $0.53 \pm 0.37^{b}$ & $14.61 \pm 3.86^{\mathrm{a}}$ \\
\hline AR & $36.93 \pm 6.72^{\mathrm{a}}$ & $3.49 \pm 0.59^{\mathrm{a}}$ & $76.98 \pm 20.43^{\mathrm{a}}$ & $0.25 \pm 0.11^{b}$ & $13.48 \pm 3.74^{\mathrm{a}}$ \\
\hline PM & $23.86 \pm 5.12^{\mathrm{b}}$ & $0.48 \pm 0.16^{\mathrm{c}}$ & $38.94 \pm 8.09^{b}$ & $3.92 \pm 0.52^{\mathrm{a}}$ & $20.70 \pm 3.83^{\mathrm{a}}$ \\
\hline
\end{tabular}

$\mathrm{SF}$, 米槠天然次生林; $\mathrm{AR}$, 米槠人工促进天然更新林; $\mathrm{PM}$ ，马尾松人工林。不同小写字母表示不同林分间差异显著 $(p<0.05)$ 。

SF, natural secondary forest of Castanopsis carlesii; AR, artificial-assisted natural regeneration forest of Castanopsis carlesii; PM, plantation of Pinus massoniana. Different lowercase letters indicate significant difference among different stands $(p<0.05)$.

呈正相关关系; $D O N$ 与 $\beta \mathrm{G}$ 呈正相关关系，且 $\beta \mathrm{G}$ 与 $\mathrm{PEO}$, 以及CBH与PHO之间都是显著负相关关系。

\section{3 讨论}

\section{1 不同森林类型对土壤碳氮含量的影响}

植被对土壤物理、化学和生物学过程有重要影 响(杨万勤和王开运, 2004)，地上调落物和植物根系 是土壤主要的有机养分供应者和养分归还者。本研
究中 SOC、TN含量大小顺序为 $\mathrm{AR}>\mathrm{SF}>\mathrm{PM}$, 这一 方面是由于阔叶林调落物量高于针叶林, 针叶林马 尾松调落物中含有相对较多难以分解的化合物，而 米槠调落物中含有较多易分解的化合物(万晓华等, 2014), 另一方面是因为造林初期炼山等因素使马 尾松人工林有机质流失较多; 3 种林分中PM的SOC、 $\mathrm{TN} 、 \mathrm{NH}_{4}^{+}-\mathrm{N} 、 \mathrm{DOC} 、 \mathrm{DON}$ 浓度低于SF和AR，在相 同立地条件下森林类型更替后的针叶人工林土壤肥

www.plant-ecology.com 


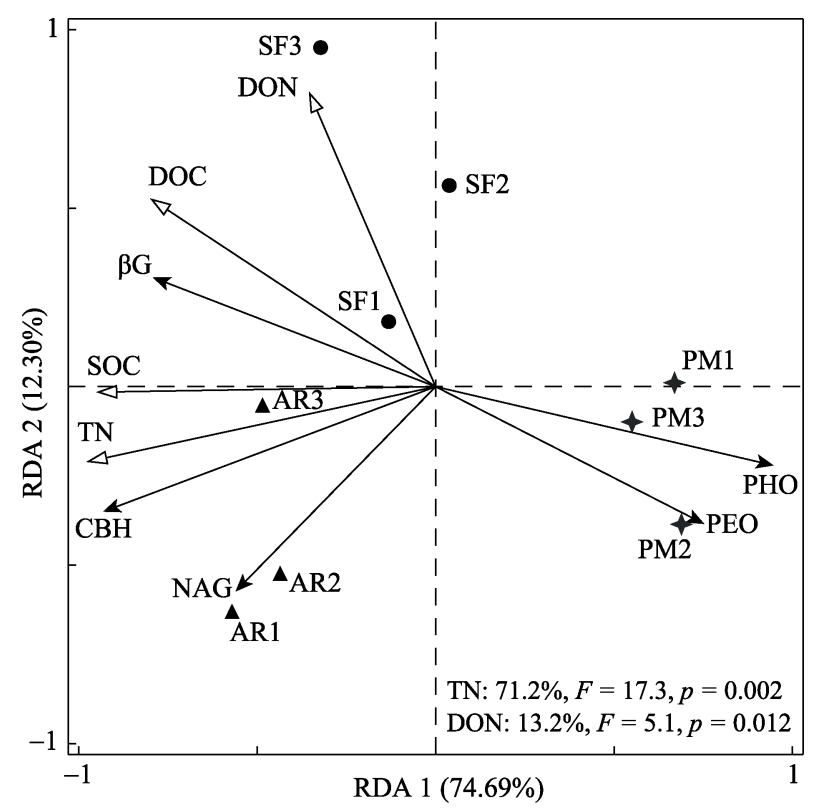

$\beta \mathrm{G}, \beta$-葡萄糖苷酶 $\beta$-glucosidase

$\mathrm{CBH}$, 纤维素水解酶 Cellulose hydrolysis

NAG, $\beta$-N-乙酰氨基葡萄糖苗酶 $\beta-\mathrm{N}$-acetylglucosaminidase PHO, 酚氧化酶 Phenol oxidase PEO, 过氧化物酶 Peroxidase

图2 不同林分土壤环境因子对土壤酶活性影响的圥余分析 (RDA)。SF1、SF2、SF3表示米槠次生林样地的3个平行重复; $\mathrm{AR} 1 、 \mathrm{AR} 2 、 \mathrm{AR} 3$ 表示米槠人工促进天然更新林样地的 3 个平 行重复; PM1、PM2、PM3表示马尾松人工林样地的 3 个平行 重复; DON, 可溶性有机氮; DOC, 可溶性有机碳; SOC, 土壤 有机碳; $\mathrm{TN}$, 总氮。图右下角变量注释表示对土壤酶变化有 显著影响作用的环境因子的相应解释比例。

Fig. 2 Redundancy analysis (RDA) of the effect of soil environmental factors on soil enzyme activity in different forest types. SF1, SF2, SF3 represent three parallel replicates of the secondary broadleaved forests of Castanopsis carlesii plot; AR1, AR2, AR3 represent three parallel replicates of the Human-assisted naturally regenerated forests of Castanopsis carlesii plot; PM1, PM2, PM3 represent three parallel replicates representing the Human-assisted naturally regenerated forests of Pinus massoniana plots of Pinus massoniana plantation. DON, dissolved organic nitrogen; DOC, dissolved organic carbon; SOC, soil organic carbon; TN, total nitrogen. The notes of variables in lower right corner of the plot represents the corresponding proportion of environmental factors that have a significant effect on soil enzyme changes.

力很难恢复。氮是植物重要的营养元素(张文鹏等, 2016; 赵宏鬼等, 2016), $\mathrm{NH}_{4}^{+}-\mathrm{N}^{2}$ 和 $\mathrm{NO}_{3}^{-}-\mathrm{N}$ 均为水溶性, 可被植物直接吸收利用(孟盈等, 2001)。本研究中3 种林分土壤 $\mathrm{NH}_{4}^{+}-\mathrm{N}$ 的含量与土壤 $\mathrm{TN}$ 的含量趋势一 致, $\mathrm{SF}$ 和 $\mathrm{AR}$ 的显著高于 $\mathrm{PM}$, 且 $\mathrm{AR}$ 最高; 这很可能 说明了 $\mathrm{NH}_{4}^{+}-\mathrm{N}$ 主要来自于土壤 $\mathrm{TN}$ 的矿化。 $\mathrm{NO}_{3}^{-}-\mathrm{N}$ 在 3 种林分中含量无显著差异且都较低, 一是因为植 物偏向吸收 $\mathrm{NH}_{4}^{+}-\mathrm{N}$, 土壤对 $\mathrm{NO}_{3}^{-}-\mathrm{N}$ 几乎不吸附(暮晓 改等, 2012), 易于从土壤尤其是阴离子交换能力差
的土壤淋溶流失; 二是因为低的土壤 $\mathrm{pH}$ 值对硝化细 菌的生长具有抑制作用(Keeney, 1980), 使硝化作用 减弱从而使 $\mathrm{NO}_{3}^{-}-\mathrm{N}$ 含量降低。同时硝态氮也会通过 反硝化作用变为易挥发的气体而减少(莫江明等, 2004)。

DOM主要来源于新近调落物、土壤腐殖质及根 系分泌物(Camino-Serrano et al., 2014), 所以树种对 DOM具有显著影响(万菁娟等, 2016)。在本研究中, $\mathrm{DOC} 、 \mathrm{DON}$ 的变化趋势均为 $\mathrm{SF}>\mathrm{AR}>\mathrm{PM}$, 其中PM 的DOC含量显著低于 $\mathrm{SF}$ 和AR (表3), 这是由于 $\mathrm{PM}$ 属于针叶林, 而 $\mathrm{SF}$ 和 $\mathrm{AR}$ 属于阔叶林。康根丽等 (2014b)研究发现, 阔叶树叶片调落物产生的DOC、 $D O N$ 浓度高于针叶树叶。AI可以指示DOM中芳香类 化合物的多少，而 $H I X_{\mathrm{em}}$ 可以用来表征DOM的腐殖 化程度; 本研究中 3 种林分土壤 DOM的 $A I$ 和 $H I X_{\mathrm{em}}$ 的趋势相反。作者所在的森林土壤有机质课题组以 前的研究发现马尾松调落物中含有相对较多难以分 解的、疏水性芳香族化合物，而米槠调落物中含有 较多易分解的、亲水性低分子量化合物(万晓华等, 2014), 所以SF和AR土壤为微生物提供了更多的可 利用能量和养分, $H I X_{\mathrm{em}}$ 也高。SF和AR的建群树种虽 然都是米槠, 但前者的林下植被较多, 而林下植被 如芒萁往往会释放 $A I$ 较低的 DOM (康根丽等, 2014a), 所以 SF土壤DOM的 $A I$ 最低, 更有利于微生 物的分解。

\section{2 不同森林类型对酶活性的影响及关键驱动因子}

作为催化土壤中众多生化反应的主要承载体, 土壤酶活性会受到一系列理化因子及生物因子的影 响。调落物和根系的改变会引起土壤养分的变化 (Bending et al., 2002; 王春阳等, 2011), 所以森林类 型对酶的活性有着重要的影响。

在本研究涉及的 5 种酶之中, 活性最高的是 $\mathrm{NAG}$, 说明了 $\mathrm{N}$ 转化在亚热带森林土壤中的重要 性。AR土壤NAG活性显著高于 SF和PM $(p<0.05)$, $\mathrm{NAG}$ 活性顺序与土壤 $\mathrm{TN}$ 和 $\mathrm{NH}_{4}^{+}-\mathrm{N}$ 的趋势一致, 这 很可能说明了 $\mathrm{NAG}$ 是催化 $\mathrm{TN}$ 矿化为 $\mathrm{NH}_{4}^{+}-\mathrm{N}$ 的关键 酶。同时 NAG活性与土壤含水率显著正相关 $(p<$ 0.05), 这与大多研究结果(Sardans \& Peñuelas, 2005; A'Bear et al., 2014)类似。

研究中 $S F$ 和 $A R$ 土壤中 $\beta G$ 和 $\mathrm{CBH}$ 两种酶活性较 $\mathrm{PM}$ 高，而PM土壤中PEO和PHO活性高于SF和AR。 这是因为阔叶树土壤中易分解碳多, 促进了微生物 
对易分解碳的利用; 这体现了底物与酶活性之间的 正相关关系。针叶树种调落物中木质素、粗纤维、 多酚类等难溶性物质含量较高, 导致调落物难以分 解, 对土壤有机碳的影响较弱(Zhao et al., 2003)。 $\mathrm{PM}$ 土壤易分解的有机碳较少, 难分解的碳相对较 多, 所以PEO和PHO的活性就高; 这与PM中AI高于 $\mathrm{SF}$ 和 $\mathrm{AR}, \mathrm{DOC}$ 含量和 $H I X_{\mathrm{em}}$ 低于 $\mathrm{SF}$ 和 $\mathrm{AR}$ 的结果吻 合。这与前人研究结果一致: 从天然阔叶林到人工 林的转化增加了土壤中PHO的活性, 但降低了 $\mathrm{CBH}$ 的活性(Sardans \& Peñuelas, 2005)。通过相关性分析, $\mathrm{C} / \mathrm{N}$ 与 $\mathrm{PHO}$ 呈正相关关系，与其他酶没有显著关系， 而微生物中真菌在偏酸性和高 $\mathrm{C} / \mathrm{N}$ 的土壤中比例较 大(Hogberg et al., 2007), 真菌可利用较难分解的碳 源。另外, 本研究发现 $\beta G$ 和 $P E O$, 以及 $\mathrm{CBH}$ 和 $\mathrm{PHO}$ 之间都是显著负相关关系, 且PHO和PEO活性小于 $\beta \mathrm{G}$ 和 $\mathrm{CBH}$, 这说明微生物利用有机碳往往有一定 的选择性，更倾向于利用易分解的有机质。

$\mathrm{RDA}$ 显示 $\mathrm{TN}$ 和 DON是3种森林类型表层土壤 酶活性的主要影响因子, 并且 $\mathrm{TN}$ 与 $\mathrm{NAG}$ 呈显著正 相关关系(图2), 这再次反映了底物与酶活性之间的 正相关关系。中亚热带是 $\mathrm{N}$ 饱和区, 森林土壤的 $\mathrm{N}$ 相 对富集(Lu et al., 2013), N在本地区发挥着养分利用 的引领作用。有研究结果证实土壤DOM周转是元素 循环的主要途径(Currie et al., 1996), DON是微生物 最易利用的有机氮源, 从而刺激相关酶的活性, 所 以DON对森林表层土壤酶的影响很大。在N循环过 程中土壤固态氮可能要先转变为DON后才能被微 生物利用分解成 $\mathrm{NH}_{4}^{+}-\mathrm{N}$ 和 $\mathrm{NO}_{3}^{-}-\mathrm{N}$ 。同时 3 种林分 $\mathrm{DON}$ 没有显著差异, 但是 $\mathrm{NH}_{4}^{+}-\mathrm{N}$ 有显著差异, 这很可能 说明了 $\mathrm{DON}$ 到 $\mathrm{NH}_{4}^{+}-\mathrm{N}$ 的矿化速率较快, 这与 $\mathrm{NAG}$ 活 性最高相一致。虽然是氮饱和区, 但土壤氮转化酶 活性仍然较高, 说明土壤可利用性氮不足。土壤氮 转化酶活性越高土壤中可利用性氮越缺乏。有可能 是微生物自身对氮的需求较大; 也有可能是微生物 为了得到更多的碳或其他营养元素, 而通过分解土 壤有机氮, 为植物提供更多氮素, 促进植物的生长, 从而固定更多的碳输入土壤, 导致土壤中的易分解 有机碳也增多, 最终满足微生物的需求(Kuzyakov $\& \mathrm{Xu}, 2013), \mathrm{TN}$ 与 $\beta \mathrm{G} 、 \mathrm{CBH}$ 之间也是显著正相关关 系, 说明 $\mathrm{N}$ 也提高了与土壤 $\mathrm{C}$ 循环相关的酶活性, 这 与Jian等(2016)的研究结果一致。有研究表明碳循环 酶潜在活性随着无机氮可用性增加而增加, 而氮循
环酶的活性随着碳可用性的增加而增加(Allison et al., 2007)。氮是微生物新陈代谢的重要养分, 当氮 含量升高时, 微生物也需要同化吸收更多的碳, 使 微生物 $\mathrm{C} / \mathrm{N}$ 保持相对稳定。

\section{4 结论}

在本研究涉及的 3 种森林土壤中, 氮是影响 $\mathrm{A}$ 层 土壤酶活性的主要因子, $\mathrm{TN} 、 \mathrm{NAG}$ 和 $\mathrm{NH}_{4}^{+}-\mathrm{N}$ 三者趋 势一致, 反映了底物对酶活性的促进作用; DON可 能是微生物矿化分解土壤氮的重要一环。同时微生 物对碳的利用有一定的选择性，更倾向于利用易分 解的有机碳; 阔叶林土壤易分解碳多, 所以 $\beta G$ 和 $\mathrm{CBH}$ 活性较高, 相反, 针叶林土壤PHO和PEO活性 较高。在氮的引领下, 3 种林分碳循环相关的水解酶 活性也提高, 说明碳氮养分循环之间存在一定的耦 合关系。在不同森林类型下, 季节差异和微生物群 落变化也会影响土壤碳氮含量和酶活性(刘捷豹等, 2017), 因此, 在本研究样地还需对季节动态和微生 物做进一步研究, 以便更好地探究土壤碳氮含量、 酶活性和微生物群落之间的联系, 从而为揭示森林 类型更替后不同林分对土壤碳氮吸存的影响机制提 供基础科学依据。

致谢 感谢福建师范大学地理科学学院彭园珍、林 燕语、刘兰英及杨柳明老师在实验过程中提供帮助。

\section{参考文献}

A'Bear AD, Jones TH, Kandeler E (2014). Interactive effects of temperature and soil moisture on fungal-mediated wood decomposition and extracellular enzyme activity. Soil Biology and Biochemistry, 70, 151-158.

Akagi J, Ádám Z, Bastida F (2007). Quantity and spectroscopic properties of soil dissolved organic matter (DOM) as a function of soil sample treatments: Air-drying and pre-incubation. Chemosphere, 69, 1040-1046.

Allison SD, Vitousek PM (2005). Responses of extracellular enzymes to simple and complex nutrient inputs. Soil Biology and Biochemistry, 37, 937-944.

Allison VJ, Condron LM, Peltzer DA (2007). Changes in enzyme activities and soil microbial community composition along carbon and nutrient gradients at the Franz Josef chronosequence, New Zealand. Soil Biology and Biochemistry, 39, 1770-1781.

Bending GD, Turner MK, Jones JE (2002). Interactions between crop residue and soil organic matter quality and the functional diversity of soil microbial communities. Soil

www.plant-ecology.com 
Biology and Biochemistry, 34, 1073-1082.

Bu XL, Wang LM, Ma WB (2010). Spectroscopic characterization of hot-water extractable organic matter from soils under four different vegetation types along an elevation gradient in the Wuyi Mountains. Geoderma, 159, 139-146.

Burns RG (1982). Enzyme activity in soil-location and a possible role in microbial ecology. Soil Biology and Biochemistry, 14, 423-427.

Burns RG, Deforest JL, Marxsen J (2013). Soil enzymes in a changing environment: Current knowledge and future directions. Soil Biology and Biochemistry, 58, 216-234.

Camino-Serrano M, Gielen B, Luyssaert S (2014). Linking variability in soil solution dissolved organic carbon to climate, soil type, and vegetation type. Global Biogeochemical Cycles, 28, 497-509.

Condron LM, Tiessen H, Turner BL (2005). Interactions of organic phosphorus in terrestrial ecosystems. Uspekhi Mat Nauk, 38, 205-206.

Currie WS, Aber JD, Mcdowell WH, Boone RD, Magill AH (1996). Vertical transport of dissolved organic C and N under long-term $\mathrm{N}$ amendments in pine and hardwood forests. Biogeochemistry, 35, 471-505.

Debosz K, Rasmussen PH, Pedersen AR (1999). Temporal variations in microbial biomass $\mathrm{C}$ and cellulolytic enzyme activity in arable soils: Effects of organic matter input. Applied Soil Ecology, 13, 209-218.

Frankenberger WT, Dick WA (1983). Relationships between enzyme activities and microbial growth and activity indices in soil. Soil Science Society of America Journal, 47, 945-951.

Ge XG, Xiao WF, Zeng LX (2012). Relationships between soil nutrient contents and soil enzyme activities in Pinus massoniana stands with different ages in Three Gorges Reservoir Area. Chinese Journal of Applied Ecology, 23, 445-451. [葛晓改, 肖文发, 曾立雄 (2012). 三峡库区 不同林龄马尾松土壤养分与酶活性的关系. 应用生态 学报, 23, 445-451.]

Hogberg M, Hogberg P, Myrold D (2007). Is microbial community composition in boreal forest soils determined by $\mathrm{pH}, \mathrm{C}-$ to-N ratio, the trees, or all three? Oecologia, 150, 590-601.

Houghton RA (2007). Balancing the global carbon budget. Annual Review of Earth \& Planetary Sciences, 35, 313-347.

Jian S, Li J, Chen J (2016). Soil extracellular enzyme activities, soil carbon and nitrogen storage under nitrogen fertilization: A meta-analysis. Soil Biology and Biochemistry, 101, $32-43$.

Jobbágy EG, Jackson RB (2000). The vertical distribution of soil organic carbon and its relation to climate and vegetation. Ecological Applications, 10, 423-436.

Kalbitz K, Geyer W, Geyer S (1999). Spectroscopic properties of dissolved humic substances-A reflection of land use history in a fen area. Biogeochemistry, 47, 219-238.

Kang GL, Yang YS, Si YT (2014a). Soluble and spectral characteristics of DOM in leaching solution from leaves and litter-fall of Pinus massoniana and Dicranopteris dichotoma. Journal of Tropical and Subtropical Botany, 22, 357-366. [康根丽, 杨玉盛, 司友涛 (2014a). 马尾松与 芒萁鲜叶及调落物水溶性有机物的溶解特征和光谱学 特征. 热带亚热带植物学报, 22, 357-366.]

Kang GL, Yang YS, Si YT (2014b). Quantities and spectral characteristics of DOM released from leaf and litterfall in Castanopsis carlesii forest and Cunninghamia lanceolata plantation. Acta Ecologica Sinica, 34, 1946-1955. [康根 丽, 杨玉盛, 司友涛 (2014b). 米槠人促更新林与杉木 人工林叶片及调落物溶解性有机物的数量和光谱学特 征. 生态学报, 34, 1946-1955.]

Keeney DR (1980). Prediction of soil nitrogen availability in forest ecosystems: A literature review. Forest Science, 26, 159-171.

Knicker H, Lüdemann HD, Haider K (1981). Incorporation studies of $\mathrm{NH}_{4}^{+}$during incubation of organic residues by ${ }^{15} \mathrm{~N}-\mathrm{CPMAS}-\mathrm{NMR}$-spectroscopy. European Journal of Soil Science, 48, 431-441.

Kuzyakov Y, Xu X (2013). Competition between roots and microorganisms for nitrogen: Mechanisms and ecological relevance. New Phytologist, 198, 656-669.

Liu JB, Chen GS, Guo JF, Yang ZJ, Li YQ, Lin CF, Yang YS (2017). Advances in research on the responses of forest soil enzymes to environmental change. Acta Ecologica Sinica, 37, 110-117. [刘捷豹, 陈光水, 郭剑芬, 杨智杰, 李一清, 林成芳, 杨玉盛 (2017). 森林土壤酶对环境变 化的响应研究进展. 生态学报, 37, 110-117.]

Lu X, Gilliam FS, Yu G, Li L (2013). Long-term nitrogen addition decreases carbon leaching in nitrogen-rich forest ecosystems. Biogeosciences Discussions, 10, 3931-3941.

Liu Z, Yang YS, Zhu JM, Si YT, Xie JS, Yang ZJ (2014). Comparative study on quantities and spectroscopic characteristics of soil dissolved organic matter between two economic forests in subtropical China. Journal of Soil \& Water Conservation, 28(5), 170-175. [刘翥, 杨玉盛, 朱 锦㯟, 司友涛, 谢锦升, 杨智杰 (2014). 中亚热带2种经 济林土壤可溶性有机质数量与光谱学特征比较. 水土 保持学报, 28(5), 170-175.]

Meng Y, Xue JY, Sha LQ, Tang JW (2001). Variations of soil $\mathrm{NH}_{4}^{+}-\mathrm{N}, \mathrm{NO}_{3}^{-}-\mathrm{N}$ and $\mathrm{N}$ mineralization under different forests in Xishuangbanna, Southwest China. Acta Phytoecologica Sinica, 25, 99-104. [孟盈, 薛敬意, 沙丽清, 唐建维 (2001). 西双版纳不同热带森林下土壤铵态氮 和硝态氮动态研究. 植物生态学报, 25, 99-104.]

Mo JM, Xue JH, Fang YT (2004). Litter decomposition and its responses to simulated $\mathrm{N}$ deposition for the major plants of Dinghushan forests in subtropical China. Acta Ecologica Sinica，24，1413-1420. [莫江明，薛璟花，方运霆 
(2004). 鼎湖山主要森林植物调落物分解及其对 $\mathrm{N}$ 沉降 的响应. 生态学报, 24, 1413-1420.]

Parfitt RL, Ross DJ, Coomes DA (2005). N and P in New Zealand soil chronosequences and relationships with foliar $\mathrm{N}$ and P. Biogeochemistry, 75, 305-328.

Saadi I, Borisover M, Armon R, Laor Y (2006). Monitoring of effluent DOM biodegradation using fluorescence, UV and DOC measurements. Chemosphere, 63, 530-539.

Saiya-Cork KR, Sinsabaugh RL, Zak DR (2002). The effects of long term nitrogen deposition on extracellular enzyme activity in an Acer saccharum forest soil. Soil Biology and Biochemistry, 34, 1309-1315.

Sardans J, Peñuelas J (2005). Drought decreases soil enzyme activity in a Mediterranean Quercus ilex L. forest. Soil Biology and Biochemistry, 37, 455-461.

Sedjo RA (1992). Temperate forest ecosystems in the global carbon cycle. AMBIO, 21(4), 274-277.

Sinsabaugh RL (2010). Phenol oxidase, peroxidase and organic matter dynamics of soil. Soil Biology and Biochemistry, 42, 391-404.

Su T, Si MR, Wang CH (2005). Effects of pretreatment, shaking and conserving method and extracting solution on results for soil mineral nitrogen. Journal of Agro-Environment Science, 24, 1238-1242. [苏涛, 司美茹, 王朝辉 (2005). 土壤矿质氮分析方法的影响因素研究. 农业环境科学 学报, 24, 1238-1242.]

Taylor JP, Wilson B, Mills MS (2002). Comparison of microbial numbers and enzymatic activities in surface soils and subsoils using various techniques. Soil Biology and Biochemistry, 34, 387-401.

Waldrop MP, Firestone MK (2004). Microbial community utilization of recalcitrant and simple carbon compounds: Impact of oak-woodland plant communities. Oecologia, 138, 275-284.

Wan JJ, Guo JF, Ji SR (2016). Effects of dissolved organic matter input on soil $\mathrm{CO}_{2}$ emission and microbial community composition in a subtropical forest. Scientia Silvae Sinicae，52(2)，106-113. [万菁娟, 郭剑芬, 纪淑蓉 (2016). 可溶性有机物输入对亚热带森林土壤 $\mathrm{CO}_{2}$ 排放 及微生物群落的影响. 林业科学, 52(2), 106-113.]

Wan XH, Huang ZQ, He ZM (2014). Effects of tree species transfer on soil dissolved organic matter pools in a reforested Chinese fir (Cunninghamia lanceolata) woodland. Chinese Journal of Applied Ecology, 25, 12-18. [万晓华, 黄志群, 何宗明 (2014). 杉木采伐迹地造林树种转变对 土壤可溶性有机质的影响. 应用生态学报, 25, 12-18.]

Wang CY, Zhou JB, Xia ZM (2011). Effects of mixed plant residues from the loess plateau on microbial biomass car- bon and nitrogen in soil. Acta Ecologica Sinica, 31, 2139-2147. [王春阳，周建斌，夏志敏 (2011). 黄土高 原区不同植物调落物搭配对土壤微生物量碳、氮的影 响. 生态学报, 31, 2139-2147.]

Wu BB, Guo JF, Wu JJ (2014). Effects of logging residues on surface soil biochemical properties and enzymatic activity. Acta Ecologica Sinica, 34, 1645-1653. [吴波波, 郭剑芬, 吴君君 (2014). 采伐剩余物对林地表层土壤生化特性 和酶活性的影响. 生态学报, 34, 1645-1653.]

Wu JS, Jiang PK, Chang SX (2010). Dissolved soil organic carbon and nitrogen were affected by conversion of native forests to plantations in subtropical China. Canadian Journal of Soil Science, 90, 27-36.

Xu C, Lin CF, Liu XF, Xiong DC, Lin WS, Chen SD, Xie JS, Yang YS (2017). Effects of forest conversion on concentrations and fluxes of dissolved organic carbon in runoff. Acta Ecologica Sinica, 37，84-92. [胥超, 林成芳, 刘小 飞，熊德成，林伟盛，陈仕东，谢锦升，杨玉盛 (2017). 森林类型更替对地表径流可溶性有机碳输出浓度和通 量的影响. 生态学报, 37, 84-92.]

Yang WQ, Wang KY (2004). Advances in forest soil enzymology. Scientia Silvae Sinicae, 40(2), 152-159. [杨万勤, 王开运 (2004). 森林土壤酶的研究进展. 林业科学, 40(2), 152-159.]

Zhang WP, Si XL, Wang WY, Gao TP, Xu DH (2016). Effects of short-term nitrogen and silicon addition on aboveground biomass and biodiversity of alpine meadow of the Qinghai-Tibetan Plateau, China. Pratacultural Science, 33, 38-45. [张文鹏，司晓林，王文银，高天鹏，徐当会 (2016). 氮硅添加对高寒草甸生物量和多样性的影响 ——青藏高原为例. 草业科学, 33, 38-45.]

Zhao HK, Ma Z, Zhang CH, Lei ZL, Yao BQ, Zhou HK (2016). The reproductive allocation of Avena sativa under different planting densities and nitrogen addition treatments. Pratacultural Science, 33, 249-258. [赵宏鬼, 马 真, 张春辉, 雷占兰, 姚步青, 周华坤 (2016). 种植密 度和施氮水平对燕麦生物量分配的影响. 草业科学, 33 , 249-258.]

Zhao JS, Zhang XD, Yuan X (2003). Characteristics and environmental significance of soil dissolved organic matter. Chinese Journal of Applied Ecology, 14, 126-130.

Zsolnay A, Baigar E, Jimenez M (1999). Differentiating with fluorescence spectroscopy the sources of dissolved organic matter in soils subjected to drying. Chemosphere, 38, $45-50$. 